\title{
IMPLEMENTASI MEDIA VISUALISASI 360 PADA PLATFORM ANDROID UNTUK PROMOSI PENJUALAN KENDARAAN BEKAS
}

\author{
Abdul Rokhim ${ }^{1)}$ Sri Ayu Lestari ${ }^{2}$ \\ ${ }^{1}$ Manajemen Informatika, ${ }^{2}$ Teknik Informatika, STMIK Yadika \\ Jl. Bader No.9, Kwangsan, Kalirejo, Kec. Bangil, Pasuruan, Jawa Timur \\ Telp. (0343) 742070 \\ IAbd.rokhim@stmik-yadika.ac.id, ${ }^{2}$ Ayulestri19@mhs.stmik-yadika.ac.id
}

\begin{abstract}
Media to promote and market an item is very important, good promotion can support the sale of goods marketed. Marketing media even now has begun to vary as advertisements on mass media, internet, brochures and other print media. Website is a media that is currently widely used in introducing products or services. Dillah Motor Tambakrejo is a dealer that sells used motorbikes and cars. utilizing Android as a smartphone communication tool has experienced development at this time, such as media tools to promote vehicles using 360 media visualization tours. Where applications can visualize used motorbikes and cars using 360 virtual media that can be seen 360 degrees of vision and consumers can know the details / parts of the motor and specifications of this motorbike
\end{abstract}

Keywords: sales, used motorbikes and cars, 360 visualization media, android.

\section{PENDAHULUAN}

Perkembangan teknologi yang semakin hari semakin pesat, memunculkan banyak inovasi baru dari teknologi. Selama ini dalam melakukan promosi sebuah kendaraan banyak cara yang dapat dilakukan, misalnya dengan menggunakan brosur, banner, dan media sosial lainnya, Yang kebanyakan fokus menggunakan media gambar 2 dimensi atau video. Pemanfaatan Android saat ini tidak hanya sebagai alat komunikasi, Salah satu inovasi pemanfaatan android adalah penggunaan teknologi visualisasi 360 tour untuk sarana pengenalan objek secara dari berbagai sisi/sudut. Dalam permasalahan promosi suatu produk hal yang paling penting adalah mengenalkan secara mendetail produk yang dijual pada calon pembeli, sehingga menimbulkan keinginan untuk membeli. Berawal dari permasalahan tersebut penulis ingin menggabungkan perkembangan teknologi dengan katalog sepeda motor menggunakan media visualisasi virtual 360 tour pada platform android. Yang bertujuan untuk membantu sales / dealer dalam mengenalkan produk sepeda motor atau mobil bekas. Dimana di dalam program aplikasi tersebut dapat memvisualisasikan sepeda motor dan mobil menggunakan media virtual 360 tour yang bisa dilihat 360 derajat penglihatan, sehingga konsumen dapat mengetahui detail / part motor dan spesifikasi motor tersebut. Permasalahan yang akan dibahas Bagaimana merancang aplikasi katalog sepeda motor dan mobil bekas dengan menerapkan media visualisasi 360 tour pada platform android.
Berdasarkan perumusan masalah di atas, tujuan dari penelitian ini adalah :

1. Dapat membantu konsumen dalam melihat detail / part sepeda motor dan mobil bekas yang dipasarkan oleh sales sebelum mereka membeli sepeda motor dan mobil bekas tersebut.

2. Konsumen bisa mendapatkan gambaran visualisasi dari sepeda motor dan mobil bekas yang di pasarkan oleh sales.

\section{METODE}

Dalam penulisan penelitian ini penulis menggunakan metodologi MDLC (Multimedia Development Life Cycle), yang terdiri dari:

1) Concept

Tahap concept (pengkonsepan) adalah tahap untuk menentukan tujuan pembuatan aplikasi katalog kendaraan berbasis platform android dengan memanfaatkan media visualisasi 360 tour yang dapat digunakan sales dalam mempromosikan kendaraan (sepeda motor/mobil).

\section{2) Design}

Design (perancangan) adalah tahap pembuatan spesifikasi mengenai user interface, arsitektur program, relasi media visualisasi 360 .

\section{3) Material Collecting}

Material collecting adalah tahap pengumpulan bahan yang sesuai dengan kebutuhan yang dikerjakan, seperti mempersiapkan kamera $360^{\circ}$, tripod $360^{\circ}$ atau Panoramic Head.

\section{4) Assembly}

Tahap assembly adalah tahap pembuatan / penyediaan semua obyek atau bahan multimedia. Pembuatan aplikasi menggunakan unity 
berdasarakn design, seperti user interface, bagan alir, dan struktur navigasi.

\section{5) Testing Tahap}

Testing (pengujian) dilakukan setelah menyelesaikan tahap pembuatan (assembly) dengan menjalankan aplikasi/program dan melihatnya apakah ada kesalahan atau tidak, dan tahap testing ini menggunakan kuesioner yang di sebarkan di beberapa target pengguna.

\section{6) Distribution}

Pada tahap ini, aplikasi yang dibuat akan didistribusi pada sales.

\subsection{Analisa Desain System}

Metode yang digunakan untuk adalah media visualisasi 360 tour tour yang bisa dilihat 360 derajat penglihatan.

2.2.1 Alur Analisis

Analisa sistem bertujuan untuk mengidentifikasi permasalahan-permasalahan yang ada pada sistem dimana aplikasi dibangun yang meliputi perangkat lunak(software), pengguna serta serta hasil analisa terhadap sistem dan elemenelemen yang terkait.

2.2.2 Use Case Diagram

Use case digunakan untuk mengetahui fungsi apa saja yang ada di dalam sistem informasi dan siapa saja yang berhak menggunakan fungsifungsi tersebut.

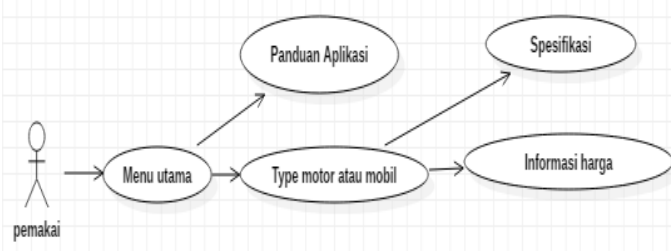

Gambar 1. Use Diagram

\subsubsection{Activity Diagram}

Activity diagram merupakan gambaran atau aktifitas dari sebuah sistem atau proses

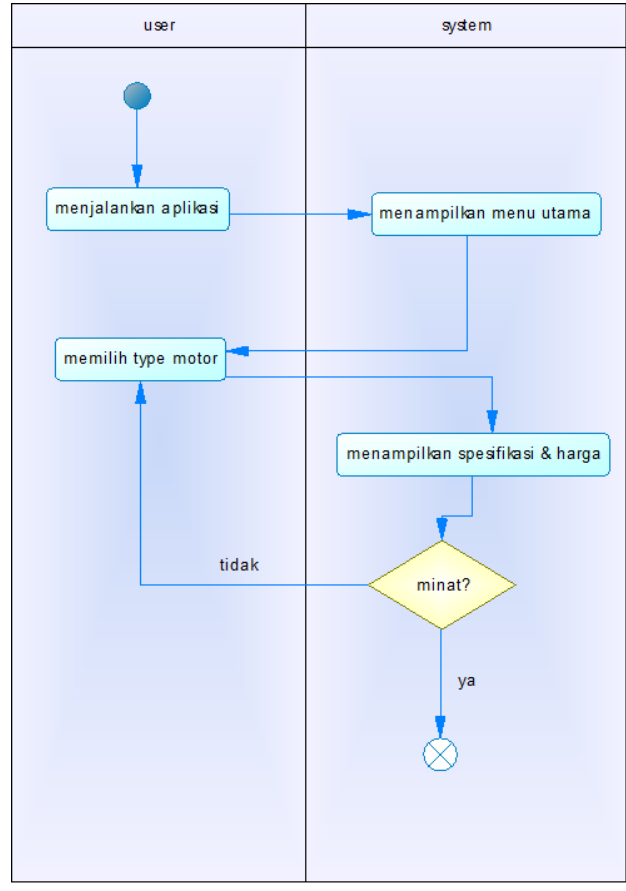

Gambar 2. Activity Diagram

\section{PEMBAHASAN}

1) Tampilan splash screen

Tampilan awal saat user pertama kali membuka aplikasi. Terdapat splash screen.
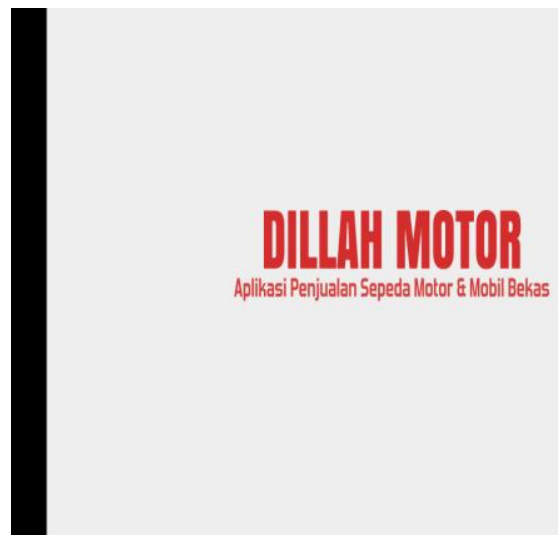

Gambar 3. Tampilan splash screen

\section{2) Tampilan Menu Utama}

Tampilan menu utama, pada halaman menu utama terdapat beberapa type - type sepeda motor dan mobil, Panduan, dan menu Keluar. 


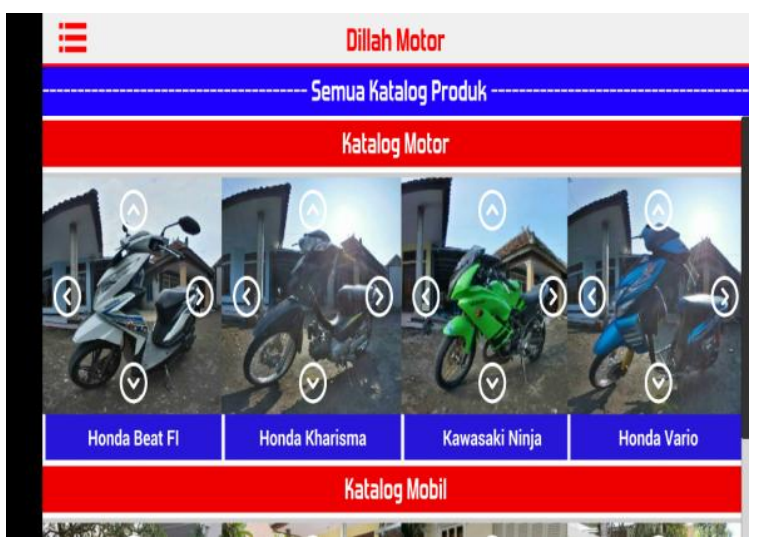

Gambar 4. Tampilan Menu Utama

3) Tampilan Menu panduan aplikasi

Halaman menu aplikasi akan menampilkan panduan tentang fitur - fitur aplikasi.

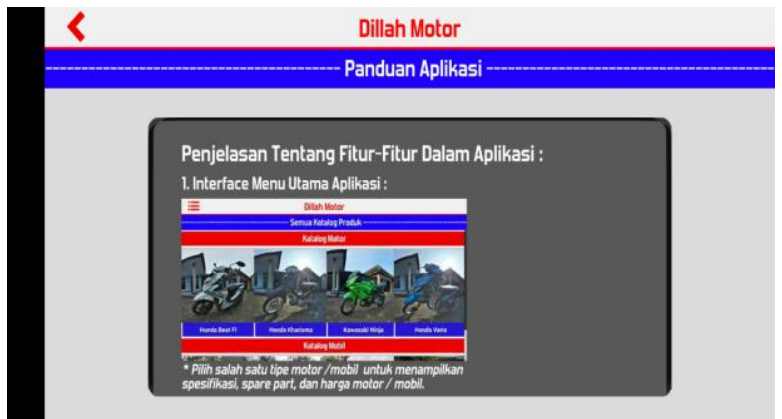

Gambar 5. Tampilan Menu panduan aplikasi

\section{4) Tampilan Menu Tentang}

Didalam menu tentang menapilkan profil dealer DILLAH MOTOR mulai dari alamat sampai kendaraan yang di jual.

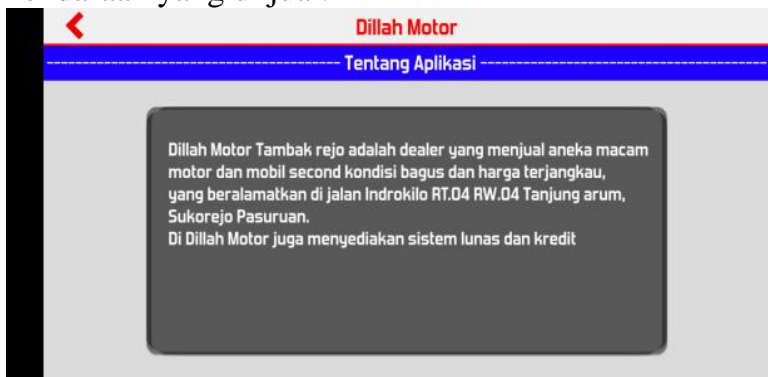

Gambar 6. Tampilan Menu Tentang

\section{5) Tampilan menu 180}

Tampilan menu 180 berisi gambar sepeda motor bekas yang dapat di lihat 180 penglihatan di setiap sisi - sisi tertentu

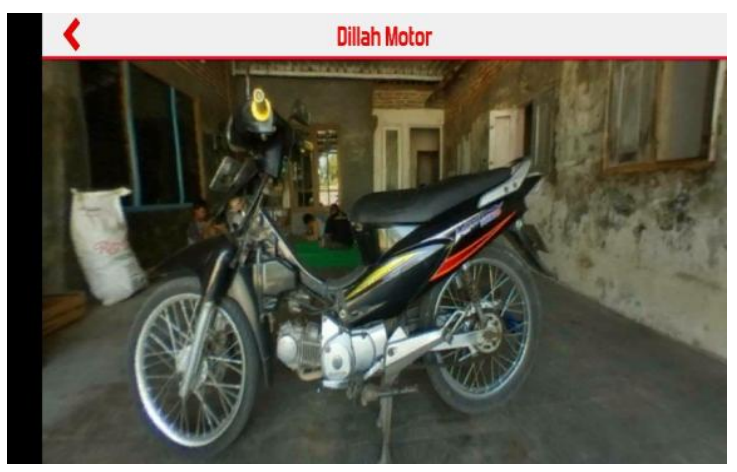

Gambar 7. Tampilan menu180

\section{6) Tampilan Menu 360}

Tampilan 360 yang dapat di lihat 360 penglihatan. Terdapat harga jual sepada motor, terdapat beberapa menu di antaranya adalah mesin, rangka \& kaki - kaki, dimensi \& berat, kapasitas, kelistrikan.

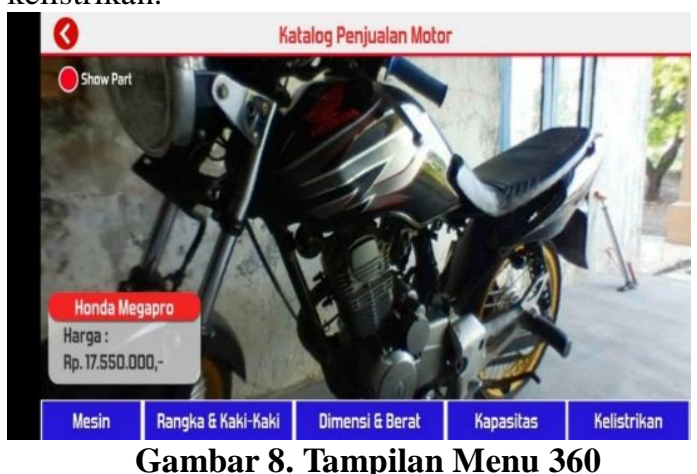

7) Tampilan Spesifikasi

Tampilan Menu spesifikasi berisi tentang tipe mesin, susunan silinder, diameter.

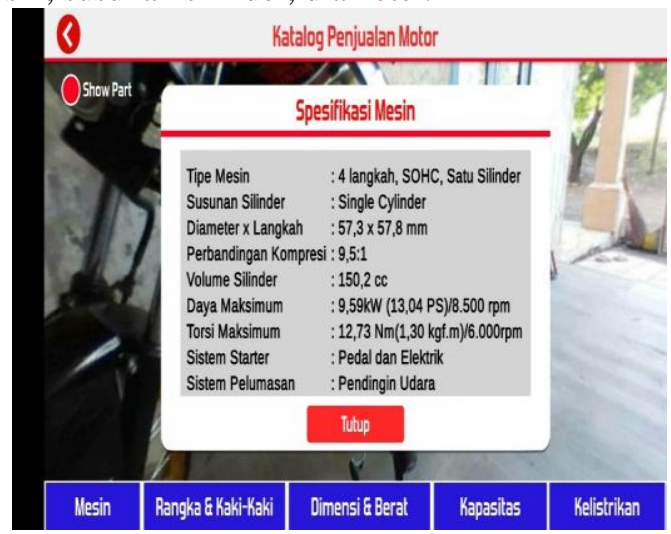

Gambar 9. Tampilan spesifikasi

\section{8) Tampilan Keluar}

Tampilan keluar berisi konfirmasi dialog apabila user menekan tombol "ya" dan "tidak". 


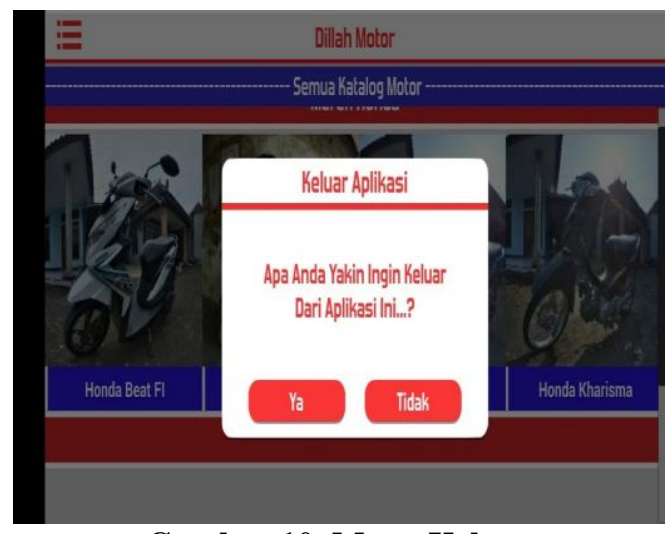

Gambar 10. Menu Keluar

\section{KESIMPULAN}

Dari hasil pembuatan aplikasi penjualan sepeda motor dan mobil bekas dalam skripsi ini penulis dapat mengambil kesimpulan, yaitu :

Aplikasi katalog sepeda motor dan mobil bekas dapat membantu sales dalam mengenalkan produk yang dijual secara mendetail.

Berdasarkan kesimpulan diatas, maka penulis mengajukan saran yang dapat dilakukan untuk perbaikan dan pengembangan aplikasi Penerapan teknologi virtual Reality Android Pada Aplikasi Katalog Kendaraan Bekas ini dengan Menambahkan fitur pemesanan dan akses database secara online pada aplikasi.

\section{PUSTAKA}

Deny Setiawan. 2018. "Penerapan Teknologi Augmented Reality Android Pada Aplikasi Katalog Perumahan".

Nikmah Isnaini, Rizky Caesar Irjayana, Hetti Hidayati, S.Kom., M.T., Fat'hah Noor Prawita, S.T., M.T, 2016. "TEMATIK PARK : APLIKASI BERBASIS VIRTUAL REALITY DENGAN PHOTO SPHERE DAN VIDEO UNTUK MEMPERKENALKAN TAMAN-TAMAN DI KOTA BANDUNG".

Farrizka Annafi,. 2014. "PENGEMBANGAN APLIKASI VIRTUAL TOUR BERBANTUAN VIDEO SEBAGAI MEDIA INFORMASI WILAYAH FAKULTAS TEKNIK UNIVERSITAS NEGERI YOGYAKARTA".

Hera Wulanratu Wulur, Steven Sentinuwo, Brave Sugiarso. 2015. “ Aplikasi Virtual tour Tempat Wisata Alam di Sulawesi Utara", E-journal Teknik Informatika, Volume 6, No. 1 (2015), ISSN : 2301-8364.

Xenna Rambing, Virginia Tulenan, Xaverius Najoan. 2017. "Virtual Reality Berbasis Video 360 Derajat pada Tari-Tarian Adat Suku Minahasa". E-Journal Teknik Informatika Vol 11, No.1 (2017) ISSN :

\section{1-8364.}

Rambing, X. S., \& Tulenan, V. (2017). Virtual Reality Berbasis Video 360 Derajat pada Tari-Tarian Adat Suku Minahasa. Jurnal Teknik Informatika, 11(1).

Putra, E. Y., Wahyudi, A., \& Tumilaar, A. (2018). Virtual Reality 360 Interaktif Wisata Digital Kota Tomohon dengan Tampilan Stereoscopic. CogITo Smart Journal, 4(1), 104-112. 